Tropical Journal of Pharmaceutical Research November 2017; 16 (11): 2645-2649

ISSN: $1596-5996$ (print); 1596-9827 (electronic)

(C) Pharmacotherapy Group, Faculty of Pharmacy, University of Benin, Benin City, 300001 Nigeria.

All rights reserved.

Available online at http://www.tjpr.org

Original Research Article

http://dx.doi.org/10.4314/tjpr.v16i11.11

\title{
Effect of vitamin C on N,N'-dimethyl-4,4'-bipyridinium dichloride-induced hepatic and renal toxicity in Swiss albino mice
}

\author{
Chohan M Shahzad ${ }^{1 \star}$, Omar MM Mohafez ${ }^{1}$, Sahibzada T Rasool ${ }^{1}$, Anroop B \\ Nair $^{2}$ \\ ${ }_{1}^{1}$ Department of Biomedical Sciences, ${ }^{2}$ Department of Pharmaceutical Sciences, College of Clinical Pharmacy, King Faisal \\ University, Al-Ahsa, Saudi Arabia
}

${ }^{*}$ For correspondence: Email: mshwhan@kfu.edu.sa; Tel: +966-538124600

Sent for review: 9 June 2017

Revised accepted: 20 October 2017

\begin{abstract}
Purpose: To evaluate the effectiveness of vitamin $C$ on paraquat-induced hepatic and renal toxicity in Swiss albino mice.

Methods: Three groups of Swiss albino mice $(n=10)$, i.e., control, paraquat $(15 \mathrm{mg} / \mathrm{kg})$ and paraquat $(15 \mathrm{mg} / \mathrm{kg})$ + vitamin $C(20 \mathrm{mg} / \mathrm{kg})$ were used in the study. The drugs were administered intraperitoneally for four days. Blood samples were collected on day 5 for determination of serum levels of liver and renal biomarkers. Thereafter, the animals were sacrificed; liver and kidney were excised and preserved in neutral formalin for histopathological analysis.

Results: The paraquat-treated animals showed higher levels of aspartate transaminase (AST), alanine transaminase $(A L T)$, serum urea and creatinine, relative to values for control. Histopathological examination of the paraquat-treated animals showed cytoplasmic vacuolar degeneration and congestion of central vein in the liver, and glomerular necrosis in the kidneys. Control and vitamin C-treated mice showed normal architecture of liver and kidney.

Conclusion: These results indicate that vitamin $C$ modulated the paraquat-induced liver and renal abnormalities in the experimental animals. Thus vitamin $C$ exerts hepatoprotective and renoprotective effects against paraquat poisoning.
\end{abstract}

Keywords: Paraquat poisoning, Liver, Kidney, Vitamin C, Toxicity, Histopathology

Tropical Journal of Pharmaceutical Research is indexed by Science Citation Index (SciSearch), Scopus, International Pharmaceutical Abstract, Chemical Abstracts, Embase, Index Copernicus, EBSCO, African Index Medicus, JournalSeek, Journal Citation Reports/Science Edition, Directory of Open Access Journals (DOAJ), African Journal Online, Bioline International, Open-J-Gate and Pharmacy Abstracts

\section{INTRODUCTION}

Pesticide poisoning is one of the key public health issues in the developing countries. Paraquat $\left.\left[\left(\mathrm{C}_{6} \mathrm{H}_{7} \mathrm{~N}\right)_{2}\right] \mathrm{Cl}_{2}\right)$, discovered in 1882 and recognized in 1995, is the most common nonselective contact herbicide which results in high morbidity and mortality [1]. It is liquid at $\mathrm{pH}$ range 6.5 to 7.5 . The herbicide is unstable in alkaline medium but stable at neutral and acidic $\mathrm{pH}$. It is inactivated by inert clays and ionic surfactants, and decomposes in the presence of ultraviolet light [2]. Paraquat is rapidly degraded by soil microorganisms into minerals. These qualities make it safe for herbicidal use. Paraquat produces reactive oxygen species by transferring electrons to molecular oxygen in light-exposed plants, thereby disrupting the process of photosynthesis [3].

Paraquat is toxic when ingested accidentally or with a suicidal intention. The acceptable daily accidental exposure to paraquat ion is 0.004 $\mathrm{mg} / \mathrm{kg}$. Pure paraquat may cause mild-to-severe 
adverse effects in mammals, such as oral mucosal irritation, ulceration, gastrointestinal discomfort, respiratory failure, hepatic failure, renal failure and death [4].

Paraquat is one of the most prominent agents that are associated with mortality from pesticide poisoning globally. It accounted for $63 \%$ of all suicidal deaths in the Caribbean islands in late 1980s. In United Kingdom, paraquat poisoning is one of the major cause of deaths ( $>50 \%$ of all pesticide associated fatalities) between 1940 and 1990. Paraquat is incompletely absorbed after ingestion and quickly distributed to lungs, liver, kidney and muscle. Approximately $90 \%$ of ingested paraquat is absorbed within $12-24 \mathrm{~h}$ and quickly eliminated in the urine. The volume of distribution of paraquat is $1.2-1.6 \mathrm{~L} / \mathrm{kg}$. Gastrointestinal decontamination and haemodialysis/haemoperfusion are the only available options for managing paraquat poisoning.

Davarpanah et al reported that vitamin E plays a beneficial role in paraquat poisoning by disrupting free radicals and preventing oxidation of unsaturated fatty acids [5]. Ascorbic acid (vitamin C) is an effective antioxidant which has the prospective to scavenge free radicals such as aqueous peroxyl radicals, superoxide anions and hydroxyl radicals [6]. Eizadi-Mood et al analysed 29 medical records of patients who received renowned antioxidants such as vitamin $C$ and $E$ together with regular treatment for paraquat poisoning and concluded that although adding antioxidant to normal treatment could not diminish the death rate, and suggested future investigations with higher amount of antioxidants [7].

The current investigation was carried out to assess the effectiveness of vitamin $C$ on paraquat-induced hepatic and renal toxicity in Swiss albino mice.

\section{EXPERIMENTAL}

\section{Animals}

Healthy, mice of BALB/c strain, weighing $30-35$ $\mathrm{g}$, were used for the study. The mice were kept in polyacrylic cages at normal temperature with equal exposure of light and dark condition and provided access to rodent pellet and water ad libitum. The animal experiment protocols for the study was permitted by University Animal Ethical Committee (no. IAEC/SSP/16/PR-013). The animal experiment procedures followed National Research Council Committee guidelines [8].

\section{Experimental design}

Thirty animals were used for the study, distributed into three different groups $(n=10)$. The group I was given normal saline only (control group), group II was administered $15 \mathrm{mg} / \mathrm{kg}$ paraquat while group III was administered paraquat (dose of $15 \mathrm{mg} / \mathrm{kg}$ ) along with vitamin C (20 mg/kg). All drugs were administered once daily through intraperitoneal injection for four days. Changes in body weight and behaviour of animals were monitored throughout the study. On day five blood samples were collected from mice in all the three groups through the retroorbital plexus under mild diethyl ether anaesthesia. Thereafter, the mice were sacrificed by cervical dislocation, and their livers and kidneys were rapidly excised. The liver and kidney samples were rinsed in normal saline and well-preserved in neutral formalin (10\%) for use in histopathological analysis.

\section{Biochemical analysis}

Serum AST and ALT were assessed to determine the extent of hepatic injury. Renal biomarkers (serum urea and creatinine levels) were also analysed. All biochemical assays were performed using as an Autoanalyzer (Hitachi, Tokyo, Japan).

\section{Histopathological analysis}

Liver and kidney sections fixed in $10 \%$ formalin were dried up in alcohol, cleaned with xylene, and fixed in paraffin blocks. Sections $(5-10 \mu \mathrm{m}$ thick) of the paraffin-processed liver and kidney tissue blocks were sectioned using microtome. Further, the segments were fixed onto glass plates and stained using routine stains such as haematoxylin and eosin. The slides were then placed in DPX medium and examined under light microscope [9].

\section{Statistical analysis}

Data are presented as mean \pm standard error (SEM). All variables were analysed for statistics by one-way ANOVA subsequently by Tukey's post-hoc comparison test. $P<0.05$ was considered statistically significant (SPSS 17.0).

\section{RESULTS}

The paraquat-treated animals showed general weakness and lost weight as result of reduced food intake. However, these signs were lower in the mice that received paraquat + vitamin $C$ than in the paraquat group. Serum levels of AST and ALT were considerably greater in the paraquattreated mice in comparison to the control group 
and the paraquat + vitamin $C$ group (Figure 1). Similarly, serum creatinine and urea were much lower in the mice group administered paraquat and vitamin $C$ than in the group that received paraquat alone (Figure 2 and Figure 3). The paraquat-treated mice showed elevated levels of AST, ALT, serum urea and serum creatinine, whereas vitamin $C$ prevented these paraquatinduced abnormalities in liver and renal markers.

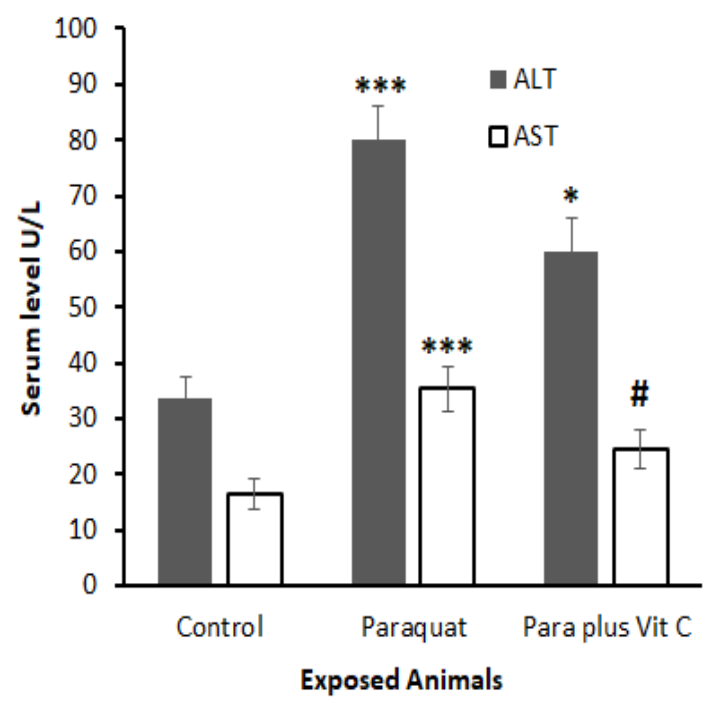

Figure 1: Comparison of the efficiency of vitamin $C$ on the paraquat induced elevated serum AST and ALT levels in Swiss albino mice. Data are mean \pm SEM ( $n$ $=10$ ); ${ }^{* * *} p<0.001,{ }^{*} p<0.05$ compare to control; ${ }^{\#} p<$ 0.05 for paraquat-treated animals

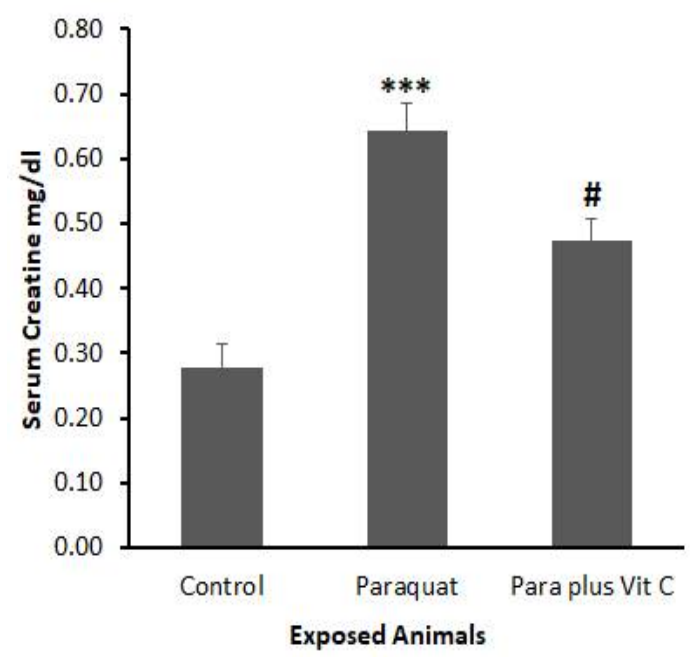

Figure 2: Comparison of the efficiency of vitamin $\mathrm{C}$ on the paraquat-induced elevated serum creatinine level in Swiss albino mice. Data are mean $\pm \operatorname{SEM}(n=10)$; ${ }^{* * *} p<0.001,{ }^{*} p<0.05$ compare to control; ${ }^{*} p<0.05$ for paraquat-treated animals

Results from histology showed that liver and kidney from mice in the control group had normal architecture (Figure 4A and D). On the other hand, the hepatocytes from paraquat-treated mice had vacuolation and congestion in central vein (Figure 4B). These paraquat-induced pathological changes were markedly ameliorated by addition of vitamin C (Figure 4C). The kidney from paraquat-treated animals showed tubular and glomerular necrosis (Figure 4E) which were mitigated by vitamin $\mathrm{C}$ (Figure 4F).

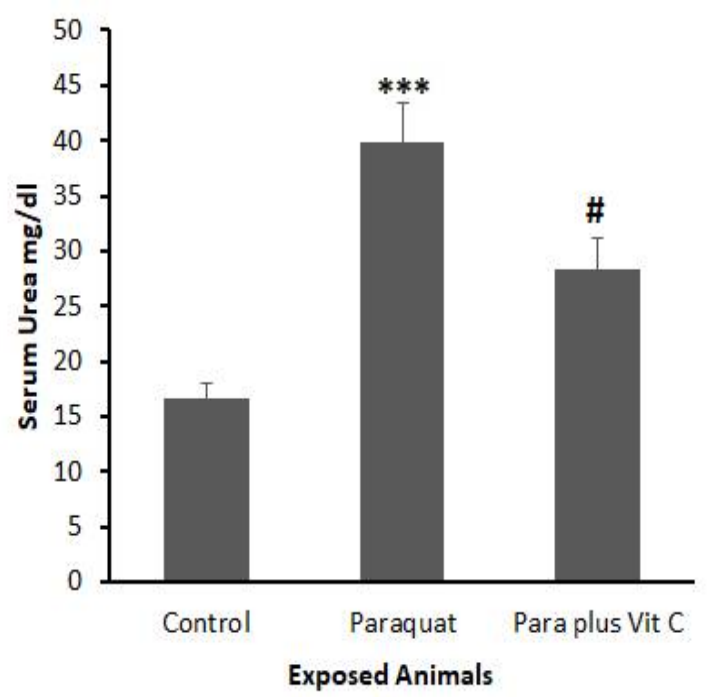

Figure 3: Comparison of the efficiency of vitamin $C$ on the paraquat induced elevated serum urea level in Swiss albino mice. Data are mean \pm SEM $(n=10)$; ${ }^{* \star *} p<0.001,{ }^{*} p<0.05$ compare to control; ${ }^{\#} p<0.05$ for paraquat-treated animals

\section{DISCUSSION}

Paraquat is a dipyridyl compound intended for weed control in most of the countries. However, the use of paraquat as an herbicide is forbidden in many nations including countries in the European Union [10]. Acute kidney injury is the main reason of death due to paraquat poisoning [11]. In a study on 14 subjects, Kanchan et al [10] reported that $78.5 \%$ had acute renal failure, 28.5 $\%$ had hepatic failure and $21.4 \%$ manifested oral ulcerations while $42.8 \%$ showed acute respiratory distress syndrome. They also observed that 10 of the 14 study subjects died from acute renal failure [10]. The present study has shown that paraquat-induced changes in renal and hepatic functions can be reversed by the simultaneous use of vitamin $\mathrm{C}$.

Previously, vitamins $C$ and $E$ were used for management of herbicide poisoning but their effects were unproven. In few clinical studies, vitamin C (4 g/day) and vitamin E $(0.25 \mathrm{~g} / \mathrm{kg})$ were used for the management of paraquat poisoning, but the results were not clear [12]. One study revealed that vitamin $\mathrm{C}$ has $\mathrm{a}$ significant antioxidant effect in patients poisoned with paraquat [13]. In this context, the objective 

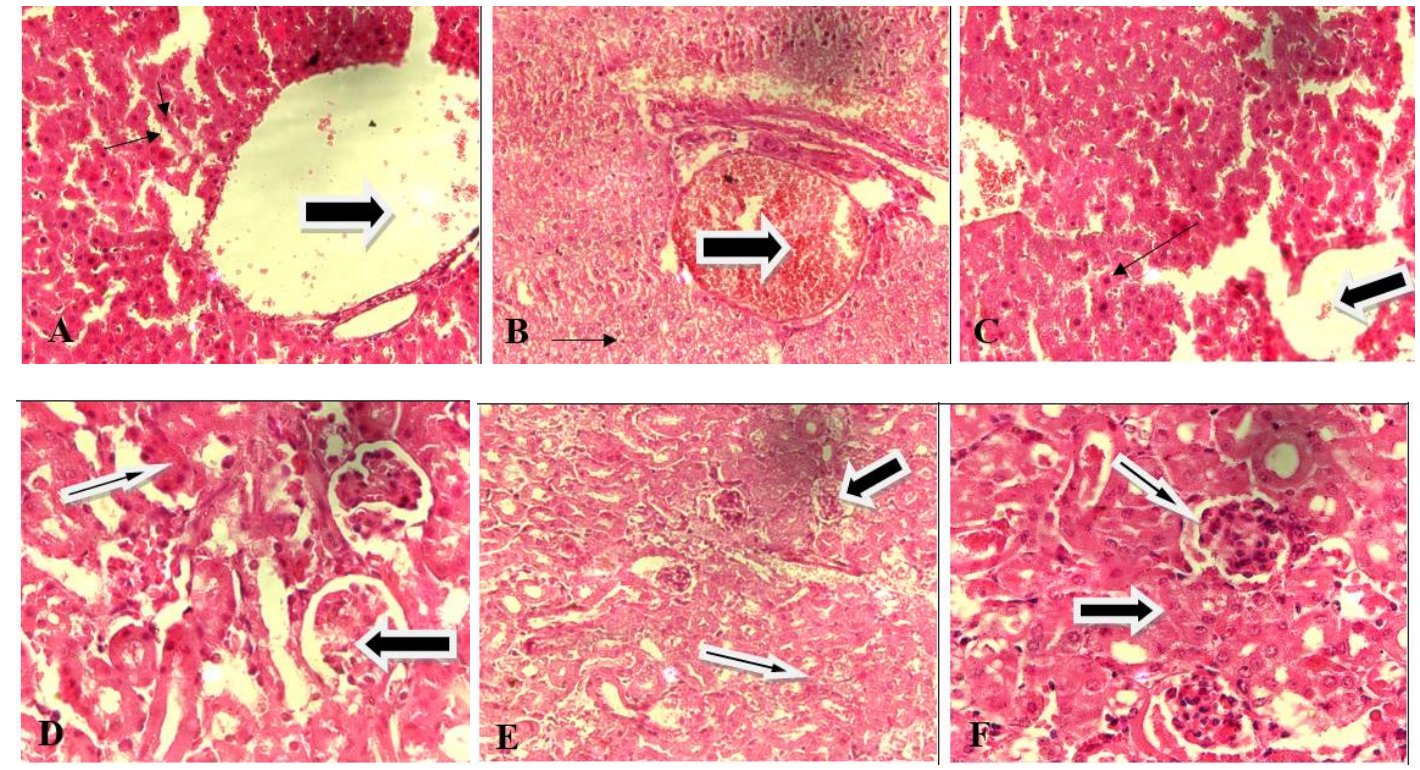

Figure 4: Histological structure of liver and kidney of investigational mice. (A) Liver of control animal showing hepatic cords radiating from the central vein (thick arrow) centrally placed nuclei (thin arrow) in hepatocytes and sinusoids (long arrow) between cords of hepatocytes (H\&E, $\times 200)$; (B) Liver of paraquat treated animal showing central vein filled with erythrocytes (thick arrow) and small vacuoles (thin arrow) coalesce with each other in the cytoplasm of hepatocytes to form those of the larger size (H\&E, $\times 200)$; (C) Liver of paraquat and vitamin C treated animal showing recovery the parenchyma of liver (thick arrow and thin arrow) $(H \& E, \times 200)$; (D) Kidney of control animal showing glomerulus (thick arrow) and tublues (thin arrow). (H\&E, $\times 200$ ); (E) Kidney of paraquat treated animal showing necrotic changes in glomeruli (thick arrow) and necrotic changes in renal tubules (thin arrow) $(\mathrm{H} \& \mathrm{E}, \times 200)$ and $(\mathrm{F}))$ Kidney of paraquat and vitamin $\mathrm{C}$ treated animal showing recovery the parenchyma of kidney (thick arrow and thin arrow) (H\&E, $\times 200)$

of the current investigation was to assess the effectiveness of vitamin $C$ on paraquat-induced hepatic and renal toxicity in mice. The results show clearly that vitamin $C$ plays a protective role against hepatic and renal toxicity brought about by paraquat.

Vitamin $C$ is an important nutrient supplement used for treatment of the common cold. It has beneficial effects in cardiovascular diseases, cancer and immunomodulatory diseases. It is an effective antioxidant and a potential scavenger of free radicals, due mainly to the ascorbate ion [14]. The protective role of vitamin C in this study is due to its antioxidant property which has been reported in previous studies $[6,15,16]$.

In the present study, the paraquat-treated animals showed increased serum levels of AST, $\mathrm{ALT}$, creatinine and urea, whereas concomitant administration of vitamin C prevented the toxic effects of paraquat as shown by biochemical and histopathological evidence. Histopathology of liver from the paraquat-treated animals showed cytoplasmic vacuolar degeneration and congestion of central veins. Necrosis of glomeruli and renal tubes were also observed in the paraquat-treated animals, a finding consistent with that of Awadalla [15]. Sakr et al has reported similar histopathological alterations in the liver of paraquat-exposed rats [17]. Awadalla et al also reported the protective nature of the vitamin $C$ in the kidney and liver of experimental animals exposed to paraquat [15]. The findings in the current study add to existing knowledge regarding the part that vitamin $\mathrm{C}$ plays in paraquat poisoning. In clinical studies, high dose of vitamin C increased survival of patients with paraquat poisoning [18]. Chang et al also demonstrated the use of larger doses of vitamin $C$ in the management of acute paraquat intoxication in Madin-Darby canine kidney (MDCK) cells [19]. Further investigation to elaborate the underlying molecular mechanisms is warranted.

\section{CONCLUSION}

Vitamin C plays a key role in reducing the deleterious effects of paraquat on liver and kidney. Additional studies are necessary to translate this finding to actual clinical application for the benefit of patients chronically exposed to paraquat poisoning.

\section{DECLARATIONS}

\section{Acknowledgement}

The authors thank the deanship of scientific 
research, king faisal university, for funding this research (project no. 150092).

\section{Conflict of Interest}

No conflict of interest associated with this work.

\section{Contribution of Authors}

The authors declare that this work was done by the authors named in this article and all liabilities pertaining to claims relating to the content of this article will be borne by them.

\section{Open Access}

This is an Open Access article that uses a funding model which does not charge readers or their institutions for access and distributed under the terms of the Creative Commons Attribution License (http://creativecommons.org/licenses/by/ 4.0) and the Budapest Open Access Initiative (http://www.budapestopenaccessinitiative.org/rea d), which permit unrestricted use, distribution, and reproduction in any medium, provided the original work is properly credited.

\section{REFERENCES}

1. Wesseling $C$, van Wendel de Joode $B$, Ruepert $C$, León $C$, Monge $P$, Hermosillo $H$, Partanen TJ. Paraquat in developing countries. Int J Occup Environ Health 2001; 7(4): 275-286.

2. Chohan MS, Zehra U, Burki W, Khilji S, Tahir M, Jafari FH. Paraquat induced toxicity in spleen of albino mice. Ann Pak Inst Med Sci 2011; 7: 6-9

3. Chohan SM, Tahir M, Lone KP, Sami W, Munir B. Paraquat induced hepatotoxicity in albino mice. Pakistan J Zool 2010; 42: 69-73.

4. Newstead CG. Cyclophosphamide treatment of paraquat poisoning. Thorax 1996; 51: 659-660.

5. Davarpanah MA, Hosseinzadeh F, Mohammadi SS. Treatment following intoxication with lethal dose of paraquat: a case report and review of literature. Iran Red Crescent Med J 2015; 17: e19373.

6. Akhtar R, Jain S, Kumar A, Bhatia S, Joshi JC, Singh D, Zaman S, Sharma $M$, Pal G, Vijayan VK, et al. Evaluation of therapeutic efficacy of ascorbic acid in patients with bronchial asthma. J Young Pharm 2016; 8: 214-219.
7. Eizadi-Mood N, Sabzghabaee AM, Yaraghi A, Montazeri K, Golabi M, Sharifian A, Sharifian A, Badri S. Effect of antioxidants on the outcome of therapy in paraquatintoxicated patients. Trop J Pharm Res 2011; 10: 27-31.

8. Guide for the Care and Use of Laboratory Animals. 8th edition. Washington DC: National Academies Press (US); 2011.

9. David AVA, Satyanarayana N, Parasuraman S, Bharathi $S$, Arulmoli R. Ameliorative effect of quercetin on methotrexate induced toxicity in sprague-dawley rats: $A$ histopathological study. Indian J Pharm Educ Res 2016; 50: S200-S208.

10. Kanchan T, Bakkannavar SM, Acharya PR. Paraquat poisoning: Analysis of an uncommon cause of fatal poisoning from Manipal, South India. Toxicol Int 2015; 22: 30-34.

11. Wunnapuk K, Mohammed F, Gawarammana I, Liu X, Verbeeck RK, Buckley NA, Roberts MS, Musuamba FT. Prediction of paraquat exposure and toxicity in clinically ill poisoned patients: a model based approach. Br J Clin Pharmacol 2014; 78: 855-866.

12. Cherukuri H, Pramoda $K$, Rohini D, Thunga G, Vijaynarayana $K$, Sreedharan $N$, Varma $M$, Pandit $V$. Demographics, clinical characteristics and management of herbicide poisoning in tertiary care hospital. Toxicol Int 2014; 21: 209-213.

13. Hong SY, Hwang KY, Lee EY, Eun SW, Cho SR, Han CS, Park YH, Chang SK. Effect of vitamin C on plasma total antioxidant status in patients with paraquat intoxication. Toxicol Lett 2002; 126: 51-59.

14. Lü J, Lin PH, Yao Q, Chen C. Chemical and molecular mechanisms of antioxidants: Experimental approaches and model systems. J Cell Mol Med 2010; 14: 840-860.

15. Awadalla EA. Efficacy of vitamin $C$ against liver and kidney damage induced by paraquat toxicity. Exp Toxicol Pathol 2012; 64: 431-434.

16. Versha $P$, Ghosh B, Anroop B, Ramanjit M. Antimicrobial activity of Alstonia scholaris leaf extracts. Indian Drugs 2003; 40: 412-413.

17. Sakr SA, Agamy El, Okdah YA. A Histopathological study of the rat ileum in paraquat poisoning. $J$ Environm Sci 2000; 20: 139-149.

18. Moon JM, Chun BJ. The efficacy of high doses of vitamin $C$ in patients with paraquat poisoning. Hum Exp Toxicol 2011; 30: 844-850.

19. Chang JB, Lin CC, Chiou JF, Mau SY, Liu TZ, Chen CH. Treatment of acute paraquat intoxication using recommended megadose of vitamin C: a reappraisal. Free Radic Res 2013; 47: 991-1001. 